\title{
Impact of Changing Temperature on Critical Thermal Maximum and Metabolic Rate of Uca perplexa and Uca crassipes
}

\author{
Nasdwiana Roni ${ }^{1 *}$, Nadiarti Nurdin Kadir ${ }^{1}$, Shinta Werorilangi ${ }^{1}$, Wayne A. Bennett ${ }^{3}$
}

${ }^{1}$ Department of Fisheries, Hasanuddin University, Makassar 90245, Indonesia

${ }^{2}$ Department of Marine Science, Hasanuddin University, Makassar 90245, Indonesia

${ }^{3}$ Biology Department, University of West Florida, 11000 University Parkway, Pensacola Florida 32514, USA

*e-mail: Nasdwiana45@gmail.com

Received: 13 February 2019 / Accepted: 14 April 2019

\begin{abstract}
This study quantifies thermal tolerance and metabolic rates for two fiddler crab species (Uca perplexa and Uca crassipes) exposed to increasing temperatures. Uca perplexa prefers sun-exposed mangal zones, while U. crassipes inhabits shaded as well as sun-exposed areas. A total forty crabs (20 crabs from each species) were collected from the Ambeua mangrove on Kaledupa Island, and transported to the Hoga Island Research Laboratory for testing. Fifteen crabs of each species were used for CTmax trials, and five crabs were used in metabolic trials. Crabs were acclimated for 10 days at 26,28 , or $30^{\circ} \mathrm{C}$ prior to experimentation. Critical Thermal Maximum (CTmax) was measured by increasing the temperature by $0.3^{\circ} \mathrm{C}$ per minute until loss of righting responses was observed. A Gilson differential respirometer was used to determine oxygen uptake at 26 and $31^{\circ} \mathrm{C}$ for each species, and the results used to calculate temperature quotient $\left(\mathrm{Q}_{10}\right)$ values. While both crab species showed an increase in thermal tolerance with increasing acclimation temperature, $U$. crassipes was more heat tolerant $\left(\mathrm{CTmax}=42.21^{\circ} \mathrm{C}\right)$, than $U$. perplexa $\left(\mathrm{CTmax}=41.95^{\circ} \mathrm{C}\right)$. Likewise, $U$. crassipes was less metabolically sensitive to temperature increase $\left(\mathrm{Q}_{10}=1.33\right)$ than $U$. perplexa, $\left(\mathrm{Q}_{10}=2.38\right)$ suggesting that $U$. crassipes is better adapted to high environmental temperature conditions.
\end{abstract}

Key words: CTmax, Acclimation, Metabolic rate, Oxygen consumption, Fiddler crab, Ambeua mangrove, Wakatobi National Park.

\section{Introduction}

Temperature is the most important environmental factor affecting ectothermic organisms, i.e., animals whose body temperature is influenced by their thermal environment (Wieser, 1973). Indeed, temperature is known to profoundly influence ectotherm life history events including survival, reproduction, distribution, movement patterns, and metabolic processes (Benfey et al., 1997; Laevastu \& Hela, 1970). While all ectotherms are well-suited to routine thermal fluctuations in their natural habitat, recent, nota- ble changes in world climatic patterns may put some ectotherms at risk of extirpation or extinction. By the end of this century sea surface temperatures in Indonesia are expected to increase by $2-5^{\circ} \mathrm{C}$ due to global warming (NOAA NCDC, 2018). Animals living in mangal zones are likely to be especially vulnerable, as mangrove habitats become dryer and warmer.

Fiddler crabs (family Ocypodidae; genus $U c a$ ), are abundant in mangrove zones but are at risk of being negatively affected by increasing environmental temperatures. The crabs play an important ecological role in mangrove 
ecosystems. As burrowing detritivores, fiddler crabs promote the exchange of nutrients, reduce anoxic sediment conditions, and control the accumulation of organic matter (Thomas \& Blum, 2010). Their bioturbation activities help maintain the balance of food chains (Pratiwi, 2010), and they are an important prey resource for higher trophic groups including large crustaceans, fish, birds and mammals (Wolff et al., 2000). The Wakatobi National Park, in Indonesia boasts a remarkably high level of fiddler crab alpha diversity, with at least seven coexisting Uca species, in the Ambeua mangrove. Fiddler crab populations in the area occupy a wide range of thermal habitats. The fiddler crab $U$. perplexa for example, prefers sun-exposed mangal areas. U. crassipes, on the other hand, supports high populations in shaded regions, with smaller, isolated groups occurring on exposed mudflats. Consequently, both groups experience different environmental temperatures regimens.

Relatively little is known about the thermal ecology of fiddler crabs or how they may respond to warming environmental conditions. The Critical Thermal maximum (CTmax) is an important metric that precisely quantifies an organism's ability to survive short-term exposure to lethal temperatures, such as challenges resulting from global warming (Madeira et al., 2013). Various studies have looked at the Critical thermal maximum and Critical thermal minimum (CTmin) of fish and crustaceans (Dabruzzi et al., 2017; Madeira et al., 2013; Eme \& Bennett, 2009; Beitinger et al., 2000), including selected fiddler crab species from several countries (Darnell et al., 2015; Faria et al., 2016; Darnell \& Darnell, 2018).

One noted effect of increasing environmental temperature on ectotherms is an acute increase in metabolic function (Campbell \& Mitchell, 2004) that can be indirectly measured as oxygen consumption rate (Kutty, 1981). Most previous fiddler crab research has looked at effects of temperature variation on fiddler crabs as it relates to morphology (Darnell \& Darnell, 2018; Saher \& Qureshi, 2012), body size (Allen et al., 2012), distribution (Mokhtari et al., 2015), behavior (Mat et al., 2017), or reproduction (Colpo \& Laura, 2017; Darnell \& Munguia, 2011). Until now, there have been no studies that have looked at the effects of increasing temperature on acclimation responses or metabolic rate in $U$. perplexa or $U$. crassipes. This study represents an important first step in determining the vulnerability of fiddler crabs facing global warming challenges. The results may be used as a base reference for carrying out conservation efforts to maintain fiddler crab biodiversity in mangrove ecosystems. The present study tests the null hypotheses that there are no significant differences in either CTmaxima, or metabolic rates between $U$. perplexa and $U$. crassipes exposed to increasing temperatures.

\section{Material and Methods}

\subsection{Study Area}

Fiddler crabs used in this study were collected in Kaledupa's Ambeua mangrove (5 $5^{\circ} 49^{\prime} \mathrm{S}$ and $\left.123^{\circ} 76^{\prime} \mathrm{E}\right)$, within the Wakatobi National Park (WNP), located in the Wakatobi district, south-east of Sulawesi, Indonesia. The Wakatobi National Park is comprised of four main Islands: Wangi-Wangi, Kaledupa, Tomia and Binongko. The islands host a variety of marine habitat types including intertidal mudflat, coral reef, seagrass meadow, and mangrove forest, all with high diversity and high levels of endemism (Unsworth et al., 2007). The Ambeua mangrove is dominated by relatively low canopy Avicennia with a fringe of Rhizophora, growing in a fine, soft mud substrate. The area experiences mixed-diurnal tides with a maximum tidal range of two meters. Water temperature fluctuates between high and low tide. During ebb tide, the mudflat areas are dominated by mudskippers (Periopthalamus spp.), assorted mollusks, and fiddler crabs. Barnes (2010) reported that Ambeua mangrove in Southeast Sulawesi, exhibits the highest alpha-diversity of fiddler crabs in the world.

\subsection{Sampling}

Uca perplexa and U. crassipes were selected for this study based on their differences in thermal habitat preference. Temperature is a major evolutionary selective factor shaping fiddler crab acclimation responses. Uca perplexa inhabits sun-exposed mangal areas almost exclusively, whereas, the highest concentrations of $U$. crassipes can be found living in shaded mangal zones, with smaller isolated groups found living in sun or partial sun areas. Crabs were collected during daytime low tide by using a bamboo stick to dig crabs from their burrows. Abiotic conditions including, air and water temperature as well as salinity were collected. All crabs were returned their site of capture following experimental trials.

\subsection{Acclimation Response Experiments}

A total of thirty fiddler crabs, fifteen of $U$. perplexa and fifteen of $U$. crassipes were used in thermal acclimation response studies. Crabs were randomly sorted, five each, into one of three treatment temperatures of $26^{\circ} \mathrm{C}, 28^{\circ} \mathrm{C}$, or $30^{\circ} \mathrm{C}$. Crabs in each treatment were housed in plastic bins containing a thin layer of mangrove mud saturated with seawater. Treatment temperatures were maintained by suspending bins in a constant-temperature, recirculating, water bath. Water bath temperatures were maintained $\left( \pm 0.3^{\circ}\right)$ by Ink Bird temperature controllers. Crab acclimation temperatures were monitored daily using an Oakton model 300 thermocouple. Crabs were acclimated at their 


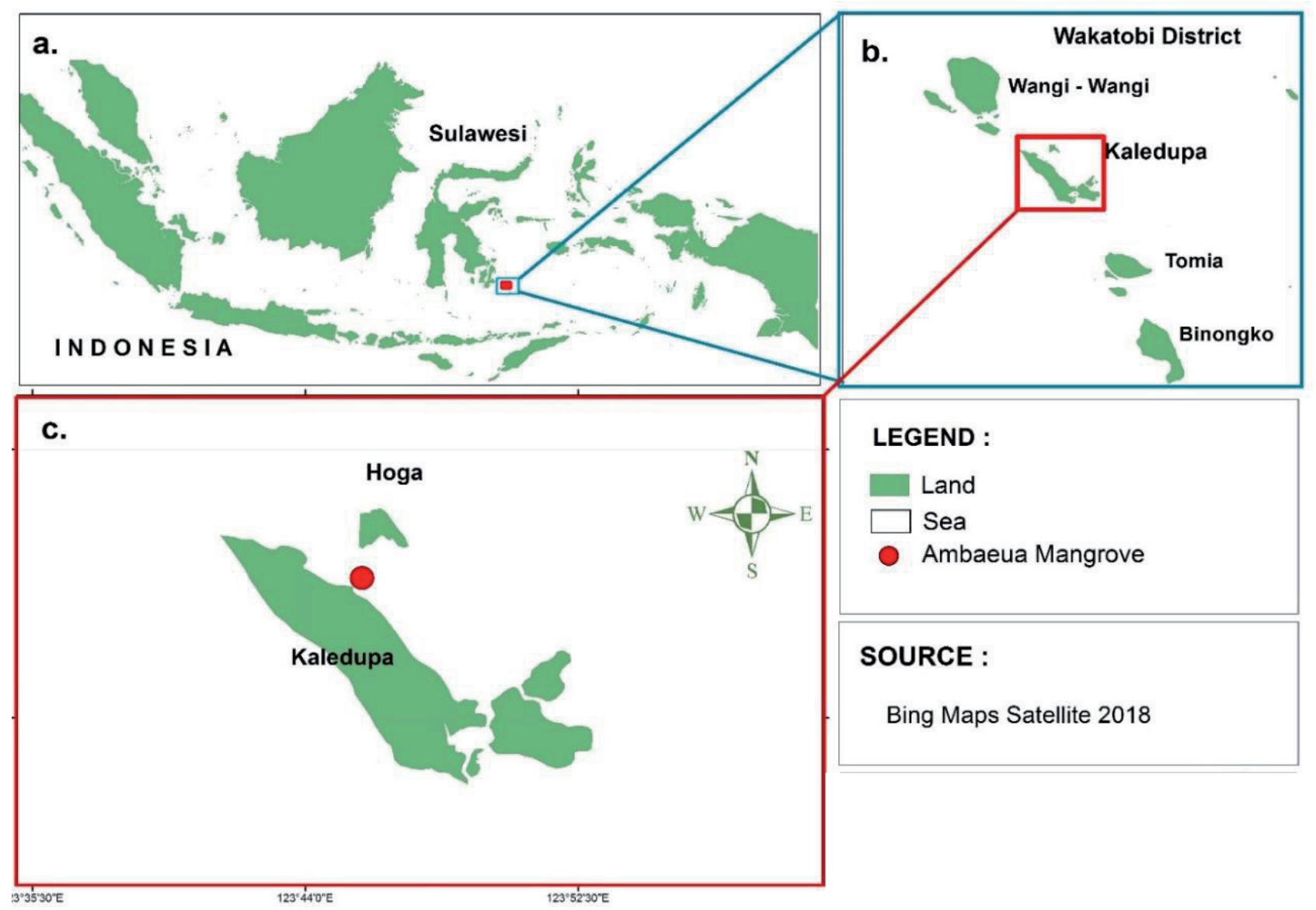

Figure 1. Maps of the study area, a - Indonesia, showing South-East Sulawesi; b - the four main islands of Wakatobi; c - Kaledupa Island

designated set point temperature for 10 days, with seawater and mud substrate renewed at 48 -hour intervals. Fiddler crabs were not fed for the 48 hours preceding the experimental trials. After the acclimation period was completed, Critical thermal maximum was determined for each individual crab from the three temperature acclimation treatments.

\section{4. Critical Thermal Maximum Experiment}

Critical Thermal Methodology was used to estimate fiddler crab CTmaxima (see Becker \& Genoway, 1979; Paladino et al., 1980 and Beitinger et al., 2000, for details). During CTmax trials, a single fiddler crab was placed into a plastic, 2-L CTmax chamber with a fiberglass screen subfloor $\sim 2 \mathrm{~cm}$ above the chamber bottom. The subfloor prevented crabs from directly contacting the chamber bottom. To assure chamber air remained fully saturated during trials, 20 $\mathrm{ml}$ of water was added to the space between the subfloor and the chamber bottom. The CTmax chamber was then placed into a recirculating, progressively heated (Finnex,
$300 \mathrm{~W}$, submersible heater) water bath. Air temperatures in the chamber were increased at approximately $0.3^{\circ} \mathrm{C}$ per minute. Crab behaviour was recorded every minute, until loss of righting response was observed (Cuculescu et al., 1998; Lutterschmidt \& Hutchison, 1997). In this experiment loss of righting response was defined as the inability of the crab to right itself when turned over on to its back quickly (Henderson et al., 2015). When loss of righting occurred, air temperature was determined (Oakton Model 300 , thermocouple), and the crab was quickly moved to a cool environment to recover. Following trials all crabs were weighed $( \pm 0.1 \mathrm{~g})$, measured (carapace width and depth $\pm 0.1 \mathrm{~cm}$ ), and returned to their previous acclimation temperature.

\subsection{Metabolic rate and temperature quotient (Q10) determinations}

Temperature quotients were calculated for five fiddler crabs of each species by first determining standard metabolic rate for crabs acclimated at $25^{\circ} \mathrm{C} \pm 0.3^{\circ} \mathrm{C}$ (approx- 
imate temperature in shaded mangal zones), and then again following an acute temperature increase to $31^{\circ} \mathrm{C} \pm$ 0.3 (simulating movement from shade to sun). Metabolic rates $\left(\mu 1 \cdot \mathrm{min}^{-1}\right)$ were determined indirectly by measuring oxygen consumption using standard Gilson Differential Respirometer protocols (Varo et al., 1993; Lighton, 2008; Morrison, 2009). For each trial, individual crabs were placed into Gilson reaction flasks, and submerged in a recirculating, $25^{\circ} \mathrm{C}$ water bath. Following a 30 minute interval to allow air temperature to reach water bath levels, reaction flasks were sealed and oxygen consumption was recorded every 5 minutes for at least 1 hour. The grand mean value of the individual metabolic estimates for each crab, was taken as the population estimate. Following the $25^{\circ} \mathrm{C}$ low temperature experiment, the water bath temperature was acutely increased to $31^{\circ} \mathrm{C}$, and the metabolic trials were repeated as described above. Following trials all crabs were weighed $( \pm 0.1 \mathrm{~g})$, measured (carapace width and depth $\pm 0.1 \mathrm{~cm}$ ), and returned to their previous acclimation temperature of $25^{\circ} \mathrm{C}$.

Crab metabolic rates determined at 25 and $31^{\circ} \mathrm{C}$ were used in $\mathrm{Q}_{10}$ calculations to estimate thermal sensitivity for both fiddler crab species. The quotient is standardized to a $10^{\circ} \mathrm{C}$ temperature change, making it a useful comparative index for assessing effects of thermal variability on ectotherm metabolic rate. In general, a $10^{\circ} \mathrm{C}$ increase results in a doubling of the metabolic rate, or a $\mathrm{Q}_{10}$ value of 2 , a responses so ubiquitous that it is often referred to as "van't Hoff's Rule". A $\mathrm{Q}_{10}$ of 1 indicates no change in metabolic rate (Dabruzzi et al., 2017). The $\mathrm{Q}_{10}$ value is calculated by the following equation (Schmidt-Nielsen, 1997):

$$
\mathrm{Q}_{10}=\left(\frac{K 2}{K 1}\right)^{\frac{109}{T 2-T 1}}
$$

where: $\mathrm{Q}_{10}$ is the temperature quotient and $\mathrm{K}_{2}$ and $\mathrm{K}_{1}$ are mean metabolic rates at temperatures $\mathrm{T}_{2}\left(31^{\circ} \mathrm{C}\right)$ and $\mathrm{T}_{1}$ $\left(25^{\circ} \mathrm{C}\right)$, respectively.

\subsection{Data Analysis}

Critical thermal maximum values for $U$. perplexa and $U$. crassipes were tested using Student's independent t-test. Whereas differences in metabolic rates within species at different temperatures were tested using a paired t-test. Comparisons of fiddler crab metabolic rate and body mass between species were also tested for significant differences using Student's independent t-test. The relationship of Critical thermal maximum on acclimation temperature was modeled using simple linear regression. Evaluations of temperature quotient values between species were made via direct comparison. All statistical decisions were based on an alpha of 0.05 .

\section{Results}

\subsection{Critical Thermal Maximum (CTmax)}

During CTmax trials, U. perplexa and U. crassipes displayed a series of stereotyped behavioral changes as air temperatures increased. In early experimental stages, at temperatures near their acclimation level, fiddler crabs exhibited periods of quiescence, punctuated by random



Figure 2. Critical thermal maximum of $U$. perplexa and $U$. crassipes acclimated at three different static temperatures 

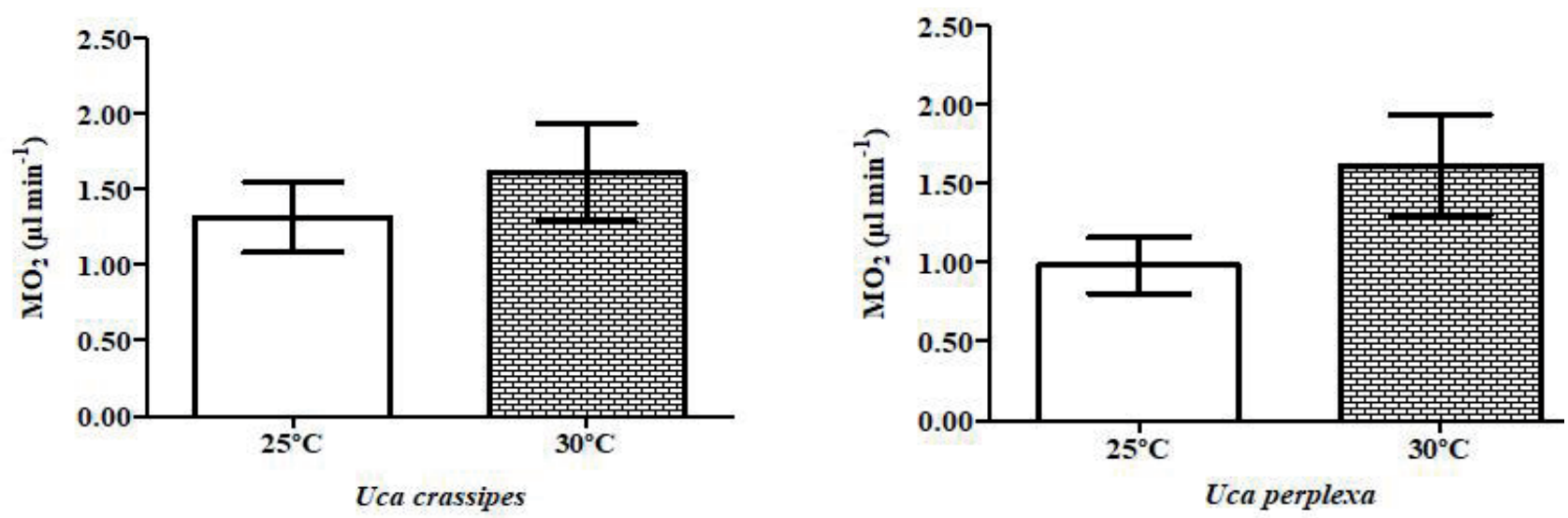

Figure 3. Oxygen consumption rate of U. perplexa and U. crassipes at 25 and $30^{\circ} \mathrm{C}$.

exploratory movements within the CTmax chamber. As chamber temperatures increased beyond acclimation levels, Uca perplexa made persistent attempts to climb the chamber walls. When exposed to similar high temperatures, however, Uca crassipes was comparatively less active than $U$. perplexa. As temperatures approached CTmax levels $\left(>33^{\circ} \mathrm{C}\right)$ both species exhibited obvious signs of heat stress including, frantic, uncoordinated movements, and discharge of a frothy mucus secretion from the mouth, perhaps as a water conservation adaptation. Mucus discharge was much more pronounced in $U$. crassipes than in $U$. perplexa.

The acclimation experiment results indicate that maximum temperature tolerance values increased with increasing acclimation temperature in both fiddler crab species (Fig. 2). However, CTmax estimates before and after acclimation suggest that there is no significant difference between temperature tolerance of $U$. crassipes and $U$. perple$x a$ when both species are acclimated to the same environmental temperature (independent t-test).

Simple linear regression of CTmax on acclimation temperature for $U$. perplexa returned an $\mathrm{r}^{2}$ value of 0.485 indicating that approximately $50 \%$ of the variability in CTmax values are explained by acclimation temperature alone, and the other $51 \%$ is influenced by other factors not considered in the experimental model. Nevertheless, analysis of variance detected a significant relationship between CTmax and acclimation temperature for $U$. perplexa (ANOVA: $\mathrm{P}=0.004)$.

Uca crassipes had the lower heat tolerance acclimation response of the two crab species. While $U$. crassipes, did demonstrate a significant regression, with an $\mathrm{r}^{2}$ value of 0.468 (ANOVA; $p=0.005$ ), the regression coefficient was somewhat lower than values seen in U. perplexa. Approximately $47 \%$ of CTmax variability explained by the independent variable with $53 \%$ of the variability influenced by other factors.

\subsection{Metabolic Rate}

The results in metabolic rate trials showed a lower average oxygen consumption rate in $U$. perplexa at low temperatures of 25 and $31^{\circ} \mathrm{C}(0.98$ and $1.62 \mu \mathrm{l} / \mathrm{min}$, respectively), compared with the average oxygen consumption rate of $U$. crassipes (1.32 and $1.62 \mu \mathrm{l} / \mathrm{min}$ ) (Fig. 3). The oxygen consumption rate of the two fiddler crabs were not sig-

Table 1. Metabolic rate and Temperature Quotient (Q10) of $U$. perplexa and U. crassipes

\begin{tabular}{|c|c|c|c|c|}
\hline $\begin{array}{c}\text { Mass (g) } \\
\text { Mean } \pm \text { SD }\end{array}$ & $\begin{array}{l}\text { Length }(\mathrm{cm}) \\
\text { Mean } \pm \text { SD }\end{array}$ & 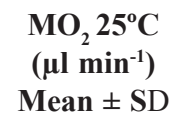 & 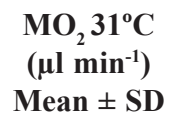 & Q10 \\
\hline \multicolumn{5}{|c|}{ Uca perplexa } \\
\hline $0.769 \pm 0.3123$ & \multicolumn{3}{|c|}{ Uca crassipes } & 2.385 \\
\hline $0.484 \pm 0.1250$ & $1.030 \pm 0.1219$ & $1.32 \pm 0.523$ & $1.62 \pm 0.724$ & 1.334 \\
\hline
\end{tabular}


nificantly different at temperatures of 25 and $31^{\circ} \mathrm{C}$ (Paired t-test, $U$. perplexa $\mathrm{p}=0.077$ and $U$. crassipes $\mathrm{p}=0.198)$. Similarly, there were no significant differences in the body weight of two fiddler crabs (Independent t-test, $\mathrm{p}>0.05$ ). The $\mathrm{Q}_{10}$ for $U$. perplexa was significantly greater than the $\mathrm{Q}_{10}$ of $U$. crassipes (Table 1).

\section{Discussion}

The critical thermal methodology has been shown to be an accurate indicator of thermal tolerance in ectothermic organisms (Beitinger et al., 2000). The importance of this index cannot be overstated. Virtually thousands of papers documenting critical maxima can be found in the scientific literature for nearly all animal phyla. Critical thermal methodology is especially important now at a time when sea surface temperatures are rising, and many ectotherm populations are migrating to cooler latitudes, and those that cannot migrate, are facing extirpation or extinction. Quantifying an ectothermic organism's ability to survive changing world temperature extremes is the critical first step in effectively managing, preserving, or restoring vulnerable populations.

At high temperature exposure, both fiddler crabs in the current study produced varying amounts of mucus, possibly related to lowering water loss through evaporation. Allen et al. (2012), for example, postulates that fiddler crabs may release mucus to maintain body moisture in the face of evaporation caused by rising temperatures. In addition to preventing water loss, some fiddler crabs also reduce activity levels as temperatures increase. Mat et al. (2017), report that some fiddler crabs may suppress metabolic rate to survive increasing temperature. This response was evident in low temperature quotient $\left(\mathrm{Q}_{10}=1.33\right)$ for $U$. crassipes in this study.

From an evolutionary perspective, habitat preference is a major factor determining acclimation capability. Access to differing thermal habitats over evolutionary time scales ultimately shapes an ectotherms' temperature tolerance (Faria et al., 2016), and may provide insight into their overall thermal tolerance strategy. The acclimation process significantly affected fiddler crab CTmaxima and explained approximately $50 \%$ of the variability seen in fiddler crab thermal tolerance (Fig. 2). Other possible factors affecting crab thermal tolerance responses include temperature fluctuations during acclimation (Darnell et al., 2015), species (Cuculescu et al., 1998), body size and condition (Darnell \& Darnell, 2018), activity (Chatterjee et al., 2014), nutrition (Koch \& Wolff, 2002), and salinity (Edney, 1961).

The CTmax of fiddler crabs increased with increasing temperature, ranging from approximately 40 to $42^{\circ} \mathrm{C}-$ temperatures lethal to most vertebrates (Bennett, 2000; Sarma et al., 2008; Cumillaf et al., 2016; Dabruzzi et al.,
2017). Their high temperature tolerance indicates that fiddler crabs may be more tolerant of increasing temperatures than vertebrates such as the mudskipper fishes with which they are syntopic (Bezerra et al., 2006; Koch \& Wolff, 2002). A reasonable assumption from these data might suggest that the most austere thermal habitats, such as those in mangroves, may be shifting more heavily toward invertebrate dominated systems, and away from vertebrate dominated systems.

At an average CTmax temperature of about $42^{\circ} \mathrm{C}, U$. perplexa and $U$. crassipes, experience a condition known as ecological-death, a point characterized by the complete loss of motor control. This is consistent with the findings of Lutterschmidt and Hutchison (1997), regarding the characteristic behaviour of crabs that experience a critical phase. Based on their average CTmax values, temperature tolerance of $U$. crassipes is somewhat higher than $U$. perplexa, possibly because $U$. perplexa dedicates more metabolic output to regulating physiological processes that become perturbed by greater temperature fluctuations (Fry, 1947) a conclusion supported by Cumillaf et al. (2016), who showed that crabs living in higher intertidal zones will be more tolerant of temperature than crabs living at lower intertidal zones. In this case, the $U$. crassipes live in the higher intertidal zone.

Metabolism is a physiological process that measures energy use in an organism. Temperature is an important factor affecting cellular respiration in such a way that increasing temperatures result in increased metabolic rates (Campbell \& Mitchell, 2004). The measurement of oxygen consumption rate in fiddler crabs showed a change that was not significant after an increase in air temperature of $6^{\circ} \mathrm{C}\left(25-31^{\circ} \mathrm{C}\right)$. This finding indicates that the temperature range, though high, was still within the limits of where the fiddler crab could meet its energy needs without an increase in metabolic rate (Karyawati et al., 2004). Aquatic organisms have different compensation levels in the face of increasing environmental temperatures. Some species show low or even no change in metabolic rates (i.e., $\mathrm{Q}_{10}=1$ ), whereas others exhibit much higher levels $\left(\mathrm{Q}_{10}>3\right)$ (Schmidt-Nielsen, 1997; Eme \& Bennett, 2009).

For $U$. crassipes, the metabolic $\mathrm{Q}_{10}$ response is quite low $\left(\mathrm{Q}_{10}=1.3\right)$. It is possible that the $U$. crassipes limits physiological activities associated with increasing metabolism during times of rising environmental temperatures. Meanwhile, $U$. perplexa more than doubles its metabolic rate following a $10^{\circ} \mathrm{C}$ temperature increase $\left(Q_{10}=2.4\right)$. This is in agreement with van't Hoff's Rule, which states that the metabolic process of ectothermic animals typically double with a $10^{\circ} \mathrm{C}$ temperature increase, expressed as a $Q_{10}$ value of $\sim 2$ (Aisami et al., 2017). Under these conditions, $U$. perplexa likely take steps to reduce the metabolic burden by altering its physiology to work more 
efficiently at a new environment (Precht et al., 1973; Hochachka \& Somero, 2002; Meyer-Rochow, 2013). Metabolic studies found $U$. crassipes to be less sensitive to acute increases in temperature, compared to $U$. perplexa. Based on the experimental result, U. crassipes is considered to be better adapted to live in habitats with higher environmental temperature ranges.

\section{Conclusion}

Fiddler crabs have a high tolerance for changes in environmental temperature. These animals exhibit different tolerance strategies based on their thermal habitat conditions. Such that $U$. crassipes inhabiting shaded mangal areas, has a higher temperature tolerance, than $U$. perplexa which lives in the sun-exposed mangal zones. In addition, the higher the acclimation temperature, the higher the thermal tolerance of fiddler crabs. Physiologically, judging by the metabolic rate and metabolic sensitivity, U. crassipes demonstrates an ability to effectively adjust its energy expenditure to better endure arduous environmental conditions than $U$. perplexa.

\section{Acknowledgements}

Special thanks to Operation Wallacea for providing the research funding and logistic support.

\section{References}

Aisami A., Yasid N.A., Johari W.L.W. \& Shukor M.Y., 2017, Estimation of the Q10 value; the temperature coeffient for the growth of Pseudomonas sp. AQ5-04 Phenol. Bioremediation Science and Technology Research 5(1): 24-16.

Allen B.J., Brook R., Tuan Y. \& Levinton J.S., 2012. Sizedependent temperature and desiccation constraints in performance capacity: Implications for sexual selection in a fiddler crab. Journal of Experimental Marine Biology and Ecology 438: 93-99.

Barnes R.S.K., 2010, A remarkable case of fiddler crab, Uca spp., alpha diversity in Wallacea. Hydrobiologia 637(1): 249.

Becker C.D. \& Genoway R.G., 1979, Evaluation of the critical thermal maximum for determining thermal tolerance of freshwater fish. Environmental Biology of Fishes 4(3): 245.

Beitinger T.L., Bennett W.A. \& McCauley R.W., 2000, Temperature tolerances of North American freshwater fishes exposed to dynamic changes in temperature. Environmental Biology of Fishes 58(3): 237-275.
Benfey T.J., Mccabe, L.E. \& Pepin P. 1997. Critical thermal maxima of diploid and triploid brook charr, Salvelinus fontinalis. Environmental Biology of Fishes 49: 259264.

Bennett W.A., 2000, Temperature tolerances of North American freshwater fishes exposed dynamic changes in temperature. Environmental Biology of Fishes 58: 237-275.

Bezerra L.E.A., Dias C.B., Santana G.X. \& Matthews-Cascon H., 2006, Spatial distribution of fiddler crabs (genus $U c a)$ in a tropical mangrove of northeast Brazil. Scientia Marina 70(4): 759-766.

Campbell R. \& Mitchell L.G., 2004, Biology: Introduction to Animal structure and function, Volume 3, Fifth Edition, Interpret: Wasmen. Erlangga Publisher, Jakarta.

Chatterjee S., Mazumdar D. \& Chakraborty S.K., 2014, Ecological role of fiddler crabs (Uca spp.) through bioturbatory activities in the coastal belt of East Midnapore, West Bengal, India. Journal of the Marine Biological Association of India 56(2): 1-25. (doi: 10.6024/ jmbai.2014.56.2.01781-03).

Colpo K.D. \& Laura S.L.G., 2017, Temperature Influences the reproduction of fiddler crabs at the southern edge of their distribution. Invertebrate Biology 10(10): 1-13.

Cuculescu M., Hyde D. \& Bowler K., 1998, Thermal tolerance of two species of marine crab, Cancer pagurus and Carcinus maenas. Journal of Thermal Biology 23: 107-110.

Cumillaf J.P., Blanc J., Paschke K., Gebauer P., Diaz F., Re Denisse, Chimal M.E., Vasquez J. \& Rosas C., 2016, Thermal biology of the sub-polar-temperate estuarine crab Hemigrapus crenulatus (Crustacea: Decapoda: Varunidae). The Company of Biologist Ltd. Biology Open 5: 220-228.

Dabruzzi T.F., Bennett W.A. \& Fangue N.A., 2017, Thermal ecology of red lionfish Pterois volitans from Southeast Sulawesi, Indonesia, with comparisons to other Scorpaenidae. Journal Aquatic Biology 26: 1-14.

Darnell M.Z. \& Munguia P., 2011, Thermoregulation as an Alternate Function of the Sexually Dimorphic Fiddler Crab Claw, University of Chicago. The American Naturalist 178(3): 419-428.

Darnell M.Z., Nicholson H.S. \& Munguia P., 2015, Thermal ecology of fiddler crabs Uca panacea: Thermal constraints and organismal responses. Journal of Thermal Biology 52: 157-165.

Darnell M.Z. \& Darnell K.M., 2018, Geographic variation in thermal tolerance and morphology in a fiddler crab sister-species pair. Marine Biology: 165:26.

Edney E.B., 1961, The water and heat relationships of Fiddler crabs (Uca spp.). Transactions of the Royal Society of South Africa 36(2): 71-91.

Eme J. \& Bennett W.A., 2009, Critical thermal tolerance polygons of tropical marine fishes from Sulawesi, Indonesia. Journal of Thermal Biology 34: 220-225. 
Faria A.C., Faleiros R.O., Brayner A.A., Alves L.C., Bianchini A., Romero C., Buranelli R.C., Mantelatto L.C. \& McNamara J.C., 2016, Macroevolution of thermal tolerance in intertidal crabs from Neotropical provinces: A phylogenetic comparative evaluation of critical limits. Ecology and Evolution 7: 3167-3176.

Fry F.E.J., 1947, Effects of the environment on animal activity. Univ. Toronto Stud. Biol. Ser. 55, Publcation of the Ontario Fisheries Research Laboratory 68: 5-62.

Henderson S., Marsham S. \& Bennett W.A., 2015, Thermal acclimation dynamics in Fiddler crabs. Marine Biology, Newcastle University, UK. (https://research.ncl. ac.uk/expeditionresearchscholarships/postergalleries/ Syndey\%20Henderson.pdf), [Accessed on 16th September 2018].

Hochachka P.W. \& Somero G.N., 2002, Biochemical adaptation. Oxford University Press, New York, NY.

Karyawati T., Hartati R. \& Rudiana E. 2004. Oxygen Consumption of Black Sea Cucumber (Holothuria atra) in Static and Dynamic Systems. Marine Science, Diponegoro University 9(3): 169-173.

Koch V. \& Wolff M., 2002, Energy budget and ecological role of mangrove epibenthos in the Caeté estuary, North Brazil. Marine Ecology Progress Series 228: 119-130.

Kutty M.N., 1981, Energy metabolism in mullet, [in:] O.H. Oren (ed.), Aquaculture of grey mullets. Cambridge University Press, London: 219-253.

Laevastu T. \& Hela I., 1970, Fisheries Oceanography. London: Fishing News, 238 pages.

Lighton J.R.B., 2008, Constant volume and constant pressure respirometry. Oxford Scholarship Online Monographs 12: 7-18.

Lutterschmidt W.I. \& Hutchison V.H., 1997, The critical thermal maximum: history and critique. Can. J. Zool. 75: 1561-1574.

Madeira D., Dias M., Roma J., Cabral H., Diniz M., Narciso L. \& Vinagre C., 2013, Critical Thermal Maximum of Coastal Organisms of the Portuguese Coas. University of Lisbon, Lisbon.

Mat A.M., Dunster D.P., Sbragaglia V., Aguzzi J. \& de la Iglesia H.O., 2017, Influence of temperature on daily locomotor activity in the crab Uca pugilator. PLOS ONE 12(4): e0175403.

Meyer-Rochow V.B., 2013, Thermal pollution: general effects and effects on cellular membranes and organelles in particular. Research Signpost Publishing, Trivandrum: $1-34$
Mokhtari M., Ghaffar M.A., Usup G. \& Cob Z.C., 2015, Determination of key environmental factors responsible for distribution patterns of fiddler crabs in a tropical mangrove ecosystem. Plos One 10(1): e0117467.

Morrison P.R., 2009, An automatic manometric respirometer. Review of Scientific Instruments 2: 264-267.

NOAA National Climate Data Center, 2018, https://www. ncdc.noaa.gov/ [Accessed on 21st May 2018].

Paladino F.V., Spotila J.R., Schubauer J.P. \& Kowalski K.T., 1980, The critical thermal maximum: a technique used to elucidate physiological stress and adaptation in fishes. Rev. Can. Biol. 39(2): 115-122.

Pratiwi R., 2010, Biology dan ecology of Uca spp. (Crustacea: Decapoda: Ocypodidae) in mangrove areas in Mahakam Delta, East Kalimantan. Neptunus 6(1): 50-59.

Precht H., Christophersen J. \& Larcher W., 1973, Temperature and life. Springer-Verlag, New York, NY.

Sarma K., Pal A.K., Ayyappan S., Das T., Manush S.M., Debnath D. \& Baruah K., 2008, Acclimation of Anabas testudineus (Bloch) to three test temperatures influences thermal tolerance and oxygen consumption. Fish Physiology and Biochemistry 36: 85-90.

Saher N. U. \& Qureshi N. A., 2012, Effect of temperature on cheliped regeneration and surviving rate in fiddler crab (Uca sp.). Pakistan Journal of Marine Science 21(1\&2): 1-12.

Schmidt-Nielsen K., 1997, Animal physiology: adaptation and environment, 5th edn. Cambridge University Press, Cambridge.

Thomas C. \& Blum K.L., 2010, Importance of the fiddler crab Uca pugnax to salt marsh soil organic matter accumulation. University of Virginia, Marine Ecology Progress Series: 412.

Unsworth R.K.F., Wylie E., Bell J.J. \& Smith D.J., 2007, Diel tropich structuring of seagrass bed fish assemblages in the Wakatobi Marine National Park, Indonesia. Estuarine Coastal and Shelf Science 72: 81-88.

Varo I., Taylor A.C. \& Amat F., 1993, Comparison of Two Methods for Measuring The Rates of Oxygen Consumption of Small Aquatic Animals (Artemia). Department of Zoology, University Glasgow, UK, 106A (3): 551-555.

Wieser W., 1973. Effect of Temperature on Ectothermic Organisms. Springer-Verlag Berlin, 298 pages.

Wolff M., Koch V. \& Isaac V., 2000, A trophic flow model of the Caeté mangrove estuary, North Brazil, with considerations of the sustainable use of its resources. Estuarine Coastal and Shelf Science 50: 789-80. 